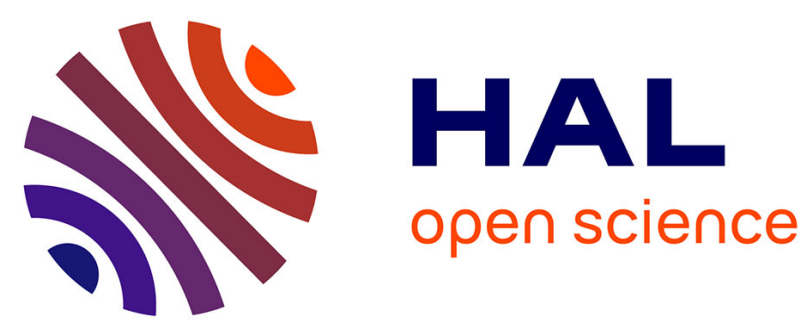

\title{
TAM and E-learning Adoption: A Philosophical Scrutiny of TAM, Its Limitations, and Prescriptions for E-learning Adoption Research
}

\author{
A. Najmul Islam, Nasreen Azad, Matti Mäntymäki, S. Samiul Islam
}

\section{- To cite this version:}

A. Najmul Islam, Nasreen Azad, Matti Mäntymäki, S. Samiul Islam. TAM and E-learning Adoption: A Philosophical Scrutiny of TAM, Its Limitations, and Prescriptions for E-learning Adoption Research. 13th Conference on e-Business, e-Services and e-Society (I3E), Nov 2014, Sanya, China. pp.164-175, 10.1007/978-3-662-45526-5_16. hal-01342144

HAL Id: hal-01342144

https://hal.inria.fr/hal-01342144

Submitted on 5 Jul 2016

HAL is a multi-disciplinary open access archive for the deposit and dissemination of scientific research documents, whether they are published or not. The documents may come from teaching and research institutions in France or abroad, or from public or private research centers.
L'archive ouverte pluridisciplinaire HAL, est destinée au dépôt et à la diffusion de documents scientifiques de niveau recherche, publiés ou non, émanant des établissements d'enseignement et de recherche français ou étrangers, des laboratoires publics ou privés. 


\title{
TAM and e-learning Adoption: A Philosophical Scrutiny of TAM, Its Limitations, and Prescriptions for e-learning Adoption Research
}

\author{
A.K.M. Najmul Islam ${ }^{1} \bowtie$, Nasreen Azad $^{2}$, Matti Mäntymäki ${ }^{1}$, S.M. Samiul Islam ${ }^{3}$ \\ ${ }^{1}$ University of Turku, Finland \\ matti.mantymaki@utu.fi \\ najmul.islam@utu.fi \\ ${ }^{2}$ Åbo Akademi University, Finland \\ nasreen.azad@abo.fi \\ ${ }^{3}$ Samsung R\&D Institute Bangladesh \\ sm.samiul@samsung.com
}

\begin{abstract}
TAM and TAM derived theories have been very popular for investigating users' e-learning adoption/post-adoption behavior. However, several philosophical holes as well as a number of limitations of TAM research have been pointed by several leading researchers in the recent years. In this paper, we discuss the philosophical holes and present our reflections and possible prescriptions about these holes while conducting research on elearning adoption/post-adoption. We also discuss the limitations of TAM research and present prescriptions about how e-learning adoption research can be conducted by addressing these limitations.
\end{abstract}

Keywords: e-learning; IS continuance model; technology acceptance model; theory of reasoned action

\section{Introduction}

The Technology Acceptance Model (TAM) [13] was originally developed from Ajzen \& Fisbein's (1980) [2] Theory of Reasoned Actions (TRA). TAM can be viewed as an adaptation of the TRA to the IS discipline. It has been regarded as one of the most influential theories in the IS discipline. It has been widely applied for explaining IT users' intention regarding IT use [32]. TAM researchers have developed a number of extensions to TAM. In addition, they have also contributed in developing the Unified Theory of Acceptance and Use of Technology (UTAUT) [55] and IS continuance model $[8,40]$ based on the TAM.

TAM has been validated across time, population, and contexts [54]. It is a wellestablished theory in IS research as well as used in other domain [32]. Venkatesh et al. (2007) [54] argued that TAM has become nearly a law-like model and it often serves as a basis for studies in other areas. TAM and its constructs have been used in areas outside the technology adoption such as information adoption [51], marketing [12],

adfa, p. 1, 2014.

(C) Springer-Verlag Berlin Heidelberg 2014 
and advertising [45]. In addition, TAM has been used as a basis for comparing SEM techniques-PLS vs. LISRELL [10].

TAM and its variants have also been used extensively in e-learning adoption research. For example, Sumak et al. (2011) [50] conducted a meta-analysis with the articles of e-learning adoption and found that $86 \%$ studies used TAM, $4 \%$ studies used UTAUT, 2\% studies used Theory of Planned Behavior (TPB) [3], and 6\% studies used other theoretical frameworks to explain users' e-learning systems adoption.

Despite its widespread use, TAM researchers have not carefully scrutinized the philosophical and epistemological foundations of the model [48]. In addition, the researchers have often ignored addressing the limitations of TAM in their adaptation of TAM to their research context. As such it has created two confusions among the scientists in the recent years. The first confusion is related to what extent TAM meets the criteria for scientific theories established for causal, positivistic explanations. The second confusion is related to how the researchers may address the TAM limitations in their research.

Silva (2007) [48] strongly argued that TAM might not be falsifiable. He continued to argue that TAM research is not progressive as the TAM researchers do not question the fundamental foundation of TAM but provide alternative hypotheses when they face anomalies. We believe these arguments are valid due to the fact that very few previous studies have addressed these issues [32, 48]. This research gap motivates this paper. We address these issues in this paper by taking e-learning adoption research as an example. Consequently, we address the following two important TAM related issues in this paper.

- First we present the philosophical holes of TAM research and discuss our reflections with these holes. We discuss possible prescriptions to these philosophical holes for e-learning adoption researchers.

- Second, we present the limitations of TAM research and discuss possible prescriptions that could be applied by e-learning adoption researchers to address those limitations.

\section{Addressing philosophical holes}

There are two major philosophical critiques regarding TAM and its variants in the prior literature [48]. These critiques are identified based on the perspective of two prominent post-positivist philosophers of science: Karl Popper and Irme Lakatos. The first critique asks: Is TAM falsifiable? The second critique asks: Is TAM research progressive? In the next we discuss these questions and present our reflections in answering these questions based on the prior literature.

\subsection{Is TAM falsifiable?}

In a particular model, all factors are represented at the same level of aggregationwhereas the actual world is a complex interweaving of different structures at many levels. Such complex world cannot be fully captured with a theory like TAM. Indeed TAM has been confirmed thousand times in the prior IS literature. Popper (1972) [43] 
in this regard states that there are no reasons to believe that a theory is scientific only because data - no matter how much of it there is - confirm it. He further states that the reason we find regularities in nature because of a mental habit that makes us jump to conclusions. He advises the scientists to keep their guard up and be suspicious of continuous confirmations. Popper (1972) [43] suggested the scientists to design experiments that aim to falsify the theory to the maximum effects. If they are successful in falsifying all or parts of their theories, they should go back to the drawing board and reformulate a new one. The alternative to this approach is to set up a theory and look for evidences for confirming the theory.

According to Silva (2007) [48], many studies utilizing the TAM targeted confirming the theory instead of falsifying it. It can be hazardous because the world is sufficiently complex and some confirming evidences can be found, no matter how unlikely the theory may be. Following Popper (1972) [43], it can be argued that researchers also need to keep their eyes open and find types of computer adoption behavior that cannot be explained by TAM. However, as discussed in the following it is very difficult to find a computer adoption that cannot be explained by TAM in prior research.

\subsubsection{Can a theory account for all type of human behavior?}

As discussed before TAM was developed from the TRA. According to Ajzen \& Fishbein (1980) [2], TRA is very general, and designed for studying virtually any human behavior. If we accept that TRA can account for all types of human behavior, then it is not a scientific theory. Popper (1972) [43] calls such theory as pseudoscience. The difference between a scientific theory and pseudo-science is that a scientific theory is falsifiable-meaning that the theory cannot explain all types of human behavior. Popper (1972) [43] notes the following.

"Every good scientific theory is a prohibition: it forbids certain things to happen. The more a theory forbids, the better it is...."

To evaluate whether TRA is scientific theory, a review of the previous psychological literature is necessary. Ogden (2003) [41] has performed such review among psychological literature. His review revealed that indeed TRA has been found weak in predicting certain behavior. However, he discovered that in such situation instead of rejecting the theory the researchers provided several explanations such as the model should be accepted but the variables were not operationalized properly, the model should be accepted but the sample characteristics may explain the results, etc.

We observed similar things in e-learning adoption research as well when the researchers employed TAM and its variants. For example, Limayem \& Cheung (2008) [49] used the IS continuance model (a TAM derived model) and habit to investigate e-learning system users' continued use behavior. They found that their combined model explained only 23\% variance of continued use. Instead of rejecting their theory, they described the following.

"We therefore believe that other significant factors (such as socio-cultural and political impacts) may affect students' decisions to continue using the IBLT. In Hong Kong, as in other Chinese communities, social factors have significant impact on usage behavior" 
Based the above findings, we argue that the TRA and TAM are falsifiable although the way these have been used in many studies might make an illusion that no data can be collected to falsify the theory. In other word we may argue that this philosophical hole is less related to the TRA or TAM framework and more related to how it has been applied in different studies. The illusion becomes even stronger when we discuss the analytic nature of the relationships among beliefs, attitude, intentions and behavior in the next.

\subsubsection{Logical-connection argument}

TAM and its variants follow the tradition of beliefs-attitude-intention-behavior relation. According to Rosenberg (1995) [46], actions are composed of desires and beliefs and that both provide actions with their meaning. He illustrates this with an example of a person named Smith carrying an umbrella. The action of Smith carrying an umbrella_-as a meaningful action — can be explained by Smith's belief that it is going to rain and desire of not getting wet. Thus, the intention of carrying an umbrella can be stated in terms of Smith's beliefs and desires. It implies that there cannot be actions without intentions.

Silva (2007) [48] referring to Rosenberg's example stated that Smith might carry an umbrella for different reasons than his belief in imminent rain and his desire to not get wet. He can carry an umbrella because it is part of his attire or because he wants to use it as a weapon. Following this, it is clear that carrying an umbrella will always linked to intentions, and identifying them will not predict the action-instead, they render an action its meaning. Hence, beliefs, intentions, and self-reported behavior measured in a cross-sectional survey are linked by definition. This is called the logical connection argument $[4,39]$.

According to the logical connection argument, intentions cannot predict behavior as these are not linked contingently but analytically. The difference between these two types of connections is that a contingent entity depends on natural process to occur, while an analytic one does not depend on natural process [19]. An analytic truth is true by definition [41]. A chemical reaction can be regarded as contingent entity as it requires the conjunction of different natural factors. On the other hand stating that a rectangle has four sides is an analytical truth. Empirical science based on experiments and observation can deal only with contingent entities.

Ogden (2003) [41] observed that the relationships in TRA are often analytical in nature. His review revealed that researchers often measure different constructs with similar statements. For example, he observes that researchers attempted to correlate perceived behavioral control with behavioral intentions, while both were measured using similar questions. Hence, finding a high correlation between these two constructs is not surprising. This makes the theory analytical. A good theory should avoid analytical truth, otherwise it will be tautological [41]. In such a case belief, attitude, and intention cannot be linked causally. Silva (2007) [48] states the problem of this in the following way.

"The problem is that intentions, stated in terms of desires and beliefs, constitute only a re-description of the action they are thought to be predicting."

It implies that when beliefs, attitude, and intentions are linked analytically, the causal relationships between these cannot be tested empirically and cannot be 
subjected to falsification. Hence, in such situation the causal links of TAM cannot be regarded as scientific according to Popper's [43] classification.

According to our critical evaluation, TAM's relationships have not been analytical in prior literature. For example, Lee et al. (2003) [32] reported examples of many studies where TAM relationships were inconsistent. We argue that if the relationships are truly analytical, then such inconsistency should not be visible. But we accept that adoption researchers are required to be more careful in their research design, especially while operationalizing the constructs of their models to avoid analytical nature. For example, the original TAM was developed to predict users' organizational IS use and cautious should be taken when operationalizing the constructs to the elearning context. We present two suggestions for the e-learning adoption researchers in relation to construct operationalization.

First, researchers should avoid similar statements in measuring different constructs. In addition, they should present the questions in a random fashion. Second, researchers should consider using objective measures of both beliefs and behavior to test the theories like TAM. Neuroscience approaches [15] can be used to collect objective data. Both suggestions can avoid analytical nature of the constructs to some extent.

\subsection{Is TAM research progressive?}

The original TAM had only two beliefs: perceived usefulness and perceived ease of use to predict IS use. When TAM is applied to explain adoption of a mobile service, it can be thought that the users adopt mobile services due to its usefulness and ease of use. But let's think about the adoption of an Enterprise Resource Planning (ERP) system in an organization. Although the system might be difficult to use and disruptive to employees' work, they use it. The TAM researchers argued that such adoption could be explained by subjective norm - that is the influence of authorities. The original TAM model did not include subjective norm, but latter whenever researchers found that TAM may not be able to explain a particular adoption, they add more variables to it.

This approach can be explained by the concept of research programme proposed by Lakatos (1970) [29]. A research programme is an organic unity, which contains both rigid and flexible components-essential, structural components as well as nonessential components. The essential structural components are the hard-core and positive heuristic of the research programme. The hard core consists of a set of theoretical assumptions to which a community of scientists is committed. The committed scientists will defend the credibility of the hard core against any threats posed by others. Yet the research programme does contain or generate components, which could be given up or replaced without abandoning the hard core. Non-essential, replaceable components of the research programme are called protective belt of the research programme. The protective belt can be viewed as the auxiliary hypotheses in defense of the hard core.

For TAM derived research programme the hard core is the basic TAM model with beliefs-attitude-intention relation. The protective belt is the additions of different researchers committed to the TAM derived research. New constructs have been added and auxiliary hypotheses have been offered to explain unexpected results without 
questioning the hard core. For example, several TAM studies [17, 37] have noticed that perceived ease of use has not been consistently linked to adoption. These studies explained the anomalies by suggesting that the role of perceived ease of use depends on the task, which is an auxiliary hypothesis according to Silva (2007) [48]. Lee et al. (2003) [32] in their review found that about $24 \%$ prior studies did not find a significant relationship between perceived ease of use and behavioral intention. However, many of these studies did not challenge the TAM, instead provided auxiliary explanations. Silva (2003) [48] noted the following in relation to this.

"In the light of Lakatos methodology of scientific research programmes, I argue that the complementary constructs and additional theoretical explanations were added by TAM researchers to protect the hard core. The additions can be considered auxiliary hypotheses that have been incorporated in the protective belt. In this sense, it is also worth mentioning that in my reading of TAM literature, I could not find papers that challenged the hard core."

Following Popper (1972) [43], such auxiliary hypotheses can be regarded as ad hoc and eventually a bad thing while following Lakatos (1970) [29], it can be argued that adjusting and developing protective belt is not necessarily a bad thing for a research programme. We argue that instead of asking whether a theory is falsifiable, the more important question is to ask whether the research programme is progressive or degenerative. A research programme is progressive if it is able to discover novel facts, develops new experimental techniques, and performs precise predictions. A research programme is degenerative if it is not able to produce novel facts by changing the protective belt. In such cases, the added hypotheses of the protective belt can be considered as ad hoc and not acceptable according to Lakatos (1970) [30].

According to our critical evaluation, the TAM derived research program has been progressive. For example, TAM researchers have added several new constructs to the original TAM such as age, gender, prior experience, management support, and voluntariness to explore the boundary conditions for TAM [32, 48]. Researchers have discovered that the psychological motivation behind initial use and subsequent use is different and thus have put more importance on post-adoption behavior than adoption behavior [8, 26, 27]. In this regard, the IS continuance model has been developed from the Expectation-Confirmation Theory (ECT) [42] to study post-adoption behavior. In addition, leading IS researchers also pointed that there are still many unexplored research areas regarding IS adoption and use, such as testing the effect of IT artifact's design characteristics on perceived ease of use, perceived usefulness and use $[6,7]$, investigating actual usage and its relation with objective performance measures [6, 32] and exploring organizational and societal adoption and use of IS [32] to name only a few.

\section{TAM limitations and possible prescriptions}

There are a number of other limitations of TAM derived studies as described by leading IS researchers [5, 6, 18]. TAM researchers must need to address these limitations for progressing TAM research. In the following we discuss these limitations and provide possible prescriptions in order to overcome these limitations in an e-learning adoption study. 


\subsection{TAM lacks design and implementation constructs}

Benbasat \& Barki (2007) [6] argued that TAM lacks investigating and understanding both design- and implementation-based antecedents of IT adoption and acceptance. The beliefs: perceived usefulness and perceived ease of use are regarded as black boxes with little research effort into investigating what makes a system useful or easy to use. As such TAM studies often lack actionable guidance for practitioners.

Indeed, TAM 2 and TAM 3 investigated the possible determinants of perceived usefulness and perceived ease of use. However, it was assumed that these two beliefs would always mediate the effects of other beliefs on behavioral intention or actual behavior. Following these assumption researchers rarely tested the direct effect of other variables on behavioral intention or actual behavior. Benbasat (2010) [7] argued that to provide more practical implications for designers and managers, researchers must need to investigate the potential effects of design and implementation characteristics related variables of an IT artifact on the construct of interest such as attitude, behavioral intention and actual behavior.

In fact prior research has found that there are variables other than perceived ease of use and perceived usefulness, which may have significant impact on behavioral intention [21]. Utilizing only two beliefs have made TAM parsimonious. However, parsimony is an Achilles' heel for TAM. In practice, although TAM predicts behavioral intention using only two beliefs, but there could be more beliefs in a particular context.

The problem related to lack of variables is even more severe for the context of elearning. TAM does not contain any specific variable related to e-learning. When researchers use TAM model to investigate e-learning system users' adoption behavior they definitely need to use variables related to e-learning. However, very few prior studies have done so [22, 23, 24]. Most of the studies used TAM in such a format that does not contain any e-learning context specific variables.

We believe that e-learning adoption researchers should consider potential design and implementation variables related to e-learning for employing TAM and its variants in their research. The researchers should keep in mind that e-learning systems are distinct from general IS at least to some extent. For example, Shee \& Wang (2008) [47] argued that an e-learning system is a highly user-oriented system that focuses on the content and how it is presented. An e-learning system offers educators and learners "possibilities", rather than "ready to use" resources. In this regard, while general IS elicits performance from individual users, e-learning is based on the cooperation between educators and students. There are many factors that may cause users' dissatisfaction and rejection of e-learning system use such as lack of cues, lack of face-to-face contact, non-verbal communication, isolation, problems with hardware/software, and network connectivity [9]. Additionally, educators' roles and teaching models also affect students' learning outcome [11].

Following these, we believe that e-learning adoption researchers using TAM should investigate the effect of such factors on perceived usefulness, perceived ease of use, attitude, behavioral intention, and actual behavior. Such research will bring valuable implications for both practitioners and researchers. 


\subsection{Limited understanding of behavior}

TAM and its variant theories uncritically accept the association between intention and actual behavior. Based on this, majority of prior research has investigated behavioral intention as the final dependent variable. The idea is that if behavioral intention is high, it will automatically improve use behavior. It is assumed that use behavior is driven by conscious intentions that result from a rational decision-making process involving beliefs, expectations, reflection on past experience, etc. and emotion such as satisfaction, frustrations, etc.

However, behavioral intention may not predict behavior. For example, De Guinea \& Markus (2009) [14] argued that emotion may also drive IS use directly. It is because: a) that the connection between emotion and behavior can occur without a person being consciously aware of the connection, and b) that the effect of emotion may not create a particular behavioral intention, but rather to derail a previously formed behavioral intention about IS use. It suggests that sudden intense emotions, such as frustration associated with a system crash or the pleasure aroused while using an IS, may be more important in its influence on behavior than intention which is driven by stable attitudes and expectations. In addition, it is often argued that frequently performed behavior becomes automatic or habitual, and it ultimately reduces the impact of intention on use [28, 49].

The above argument raises one important issue - that is intention may not predict behavior as emotions and beliefs might have stronger influence on behavior. Hence, it becomes perhaps more important to investigate usage behavior rather than intention. However, very few prior studies have investigated usage behavior and its relation with intention [32, 16, 24].

Indeed some studies measured behavior. However, most of these studies measured self-reported usage behavior instead of actual usage behavior. Self-reported usage is assumed to be a reasonable predictor of actual system usage in adoption studies [1, 25]. However, several studies have cautioned in the use of self-reported usage instead of actual usage [31, 32, 44, 49, 52]. For example, Straub et al. (1995) [49] found that research based on self-reported usage shows distinctly different results from that of actual usage. In addition, self-reported usage was also found to be the major reason for common method bias [20].

In addition, the self-reported usage itself has largely been viewed as a 'black box', and hence understanding the situation specific usage behaviors is limited [22, 53]. For example, e-learning services can be used in many situations such as at school, home, and even while moving. Thus, we suggest researchers open the usage 'black box' into situation specific actual behaviors in their future research.

\subsection{Missing adoption/usage outcomes}

TAM assumes that more use is better. In other word more utilization of a technology increases performance. Following this prior studies have put highest importance in explaining users' behavior with the target system. These studies investigated possible antecedents and determinants of system use behavior. As such these studies often ignored the outcome of system use. Many studies argued that more use might not necessarily improve individuals' or organizational performance. For example Islam 
(2013) [24] found that heavy usage of an e-learning system might not necessarily help students in their study to achieve better academic performance. However, only a few prior e-learning adoption studies verified the relation between use and learning outcomes.

Indeed, few studies have gone beyond use to explore the factors associated with learning. McGill \& Klobas (2009) [38] found that e-learning system utilization influences perceived impact on learning. Lee \& Lee (2008) [33] revealed that a number of e-learning environment quality related variables affect satisfaction with elearning. In turn, satisfaction was found to influence academic achievement. Liaw (2008) [34] found high correlation between intention to use e-learning and e-learning effectiveness. These studies provide some empirical support about the possible relationships between e-learning system use and e-learning outcomes. However, these studies have been conducted with a variety of outcome variables that use different explanatory variables and this has led to models that offer only weak theoretical support. Thus, these studies fall short in explaining the relationship between the antecedents of adoption and use of e-learning systems and their use outcomes, and the relationship between e-learning system use and use outcomes.

We suggest researchers develop complete nomological network taking into account e-learning system usage antecedents, usage, and performance outcomes in the future. Performance outcome variables could be related to both teaching and learning. Examples of teaching performance related variables are planning, managing, instructing, assessing, and collaborating. Example of learning performance related variables are perceived learning, and grade.

\section{Conclusion}

This paper conducted a scrutiny of TAM and its variants in relation to e-learning adoption research. We presented two types of critique of TAM: philosophical holes and limitations regarding missing variables. Based on our critical evaluation, TAM has served the IS researchers as a theoretical model that speaks to the unique nature of information systems. From philosophical perspective, first we asked the question: Is TAM falsifiable? We observed from prior literature that TAM is falsifiable, although the way the results have been reported in the prior literature might make an illusion that TAM is not falsifiable. Second, we asked the question: Is TAM research progressive? Again, from the prior literature, we observed that TAM research is progressive in a variety of contexts including e-learning. Overall, we found that philosophically there is no problem in applying TAM and its variants in studying elearning adoption. However, we think that TAM contains deceptively straight-forward constructs and measures. Thus, we believe that TAM should be revisited to ensure design, usage, and outcome constructs have been measured in the best possible way by e-learning adoption researchers. The researchers should develop sophisticated conceptualizations of e-learning outcomes as well as what system usage means in a specific research contexts. 


\section{References}

1. Agarwal, R. and Prasad, J. (1999). Are individual differences germane to the acceptance of new information technologies? Decision Sciences, 30(2), 361-391.

2. Ajzen, J. and Fishbein, M. (1980). Understanding attitudes and predicting social behavior. Prentice-Hall, Englewood Cliffs, NJ.

3. Ajzen, I. (1991). The theory of planned behavior. Organizational Behavior and Human Decision Processes, 50 (2), 179-211.

4. Anscombe, G.E.M. (1957). Intention (2nd Ed.). Oxford: Basil Blackwell, England.

5. Bagozzi, R. R. (2007). The legacy of the technology acceptance model and a proposal for a paradigm shift. Journal of the Association of Information Systems, 8(4), 244-254.

6. Benbasat, I. and Barki, H. (2007). Quo vadis, TAM? Journal of the Association of Information Systems, 8(4), 211-218.

7. Benbasat, I. (2010). HCI research: Future challenges and directions. AIS Transaction on Human-Computer Interaction, 2(2), 16-21.

8. Bhattacherjee, A. (2001). Understanding information systems continuance: An expectation-confirmation model. MIS Quarterly, 25(3), 251-370.

9. Buckley, K.M. (2003). Evaluation of classroom-based, web-enhanced, and web-based distance learning nutrition courses for undergraduate nursing. Journal of Nursing Education, 42(8), 367-370.

10. Chin, W.W. and Todd, P.A. (1995). On the use, usefulness and ease of use of structural equation modeling in MIS research. MIS Quarterly, 19(2), 237-246.

11. Coppola, N.W., Hiltz, S.R. and Rotter, N.G. (2002). Becoming a virtual professor: Pedagogical roles and asynchronous learning networks. Journal of Management Information Systems, 18(4), 169-189.

12. Dabholkar, P.A. and Bagozzi, R.P. (2002). An attitudinal model of technology-based selfservice: Moderating effects of consumer traits and situational factors. Journal of Academy of Marketing Science, 30(3), 184-201.

13. Davis, F.D. (1989). Perceived usefulness, perceived ease of use, and user acceptance of information technology. MIS Quarterly, 13(3), 319-340.

14. De Guinea, A.O. and Markus, M.L. (2009). Why break the habit of a lifetime? Rethinking the role of intention, habit, and emotion in continuing information technology use. MIS Quarterly, 33(3), 433-444.

15. Dimoka, A., Bagozzi, R., Banker, R., Brynjolfsson, E., Davis, F., Gupta, A., Riedl, R. (2009). NeuroIS: Hype or Hope? In: Proceedings of the 30th International Conference on Information Systems, 2009, 1-11.

16. Freeze, R.D., Alshare, K.A., Lane, P.L. and Wen, H.J. (2010). IS success model in elearning context based on students' perceptions. Journal of Information systems education, 21(2), 173-184.

17. Gefen, D. and Straub, D.W. (2000). The relative importance of perceived ease of use in IS adoption: A study of e-commerce adoption. Journal of the Association of Information Systems, 1(8), 1-28.

18. Goodhue, D.L. (2007). Comment on Benbasat and Barki's "Quo vadis TAM" article. Journal of the Association of Information Systems, 8(4), 219-222.

19. Honderich, T. (ed.) (1995). The Oxford companion to philosophy. Oxford University Press, Oxford.

20. Igbaria, M., Zinatelli, N., Cragg, P. and Cavaye, A.L.M. (1997). Personal computing acceptance factors in small firms: A structural equation model. MIS Quarterly, 21(3), 279305.

21. Islam, A.K.M.N. (2011). The determinants of the post-adoption satisfaction of educators with an e-learning system. Journal of Information Systems Education, 22(4), 319-332. 
22. Islam, A.K.M.N. (2012a). The role of perceived system quality as the educators' motivation to continue e-learning system use. AIS Transaction on Human-Computer Interaction, 4(1), 25-43.

23. Islam, A.K.M.N. and Mäntymäki, M. (2012). Continuance of professional social networking sites: A decomposed expectation-confirmation approach. In Proceedings of the International Conference on Information System (ICIS 2012), Orlando, Florida, USA.

24. Islam, A.K.M.N. (2013). Investigating e-learning system usage outcomes in the university context. Computers \& Education, 69, 387-399.

25. Jackson, C.M., Chow, S. and Leitch, R.A. (1997). Toward an understanding of the behavioral intention to use an information system. Decision Sciences, 8(2), 357-389.

26. Jasperson, J.S., Carter, P.E., and Zmud, R.W. (2005). A comprehensive conceptualization of post-adoptive behaviors associated with information technology enabled work systems. MIS Quarterly, 29(3), 525-557.

27. Karahanna, E., Straub, D.W. and Chervany, N.L. (1999). Information technology adoption across time. MIS Quarterly, 23(2), 183-213.

28. Kim, S.S., Malhotra, N.K. and Narasimhan, S. (2005). Two competing perspectives on automatic use: A theoretical and empirical comparison. Information Systems Research, 16(4), 418-432.

29. Lakatos, I. (1970). Falsification and the methodology of scientific research programmes. In: Criticism and the growth of knowledge, ed. by I. Lakatos - A. Musgrave, 91-196, Cambridge University Press.

30. Lakatos, I. (1978). The methodology of scientific research programmes: Philosophical papers volume 1, Cambridge University Press, Cambridge.

31. Lederer, A.L., Maupin, D.J., Sena, M.P. and Zhuang, Y. (2000). The technology acceptance model and the world wide web. Decision Support Systems, 29(3), 269-282.

32. Lee, Y., Kozar, K.A. and Larsen, K. (2003). The technology acceptance model: Past, present, and future. Communications of the Association for Information Systems, 12, 752780.

33. Lee, J.-K. and Lee, W.-K. (2008). The relationship of e-Learner's self-regulatory efficacy and perception of e-Learning environment quality. Computers in Human Behavior, 24(1), 32-47.

34. Liaw, S.-S. (2008). Investigating students' perceived satisfaction, behavioral intention, and effectiveness of e-learning: A case study of the Blackboard system. Computers \& Education, 51(2), 864-873.

35. Limayem, M. and Cheung, C.M.K. (2008). Understanding information systems continuance: The case of Internet-based learning technologies. Information \& Management, 45(4), 227-232.

36. Limayem, M., Hirt, S.G. and Cheung, C.M.K. (2007). How habit limits the predictive power of intention: The case of information systems continuance. MIS Quarterly, 31(4), 705-737.

37. Ma, Q. and Liu, L. (2004). The technology acceptance model: A meta-analysis of empirical findings. Journal of Organization and End User Computing, 16(1), 59-72.

38. McGill, T.J. and Klobas, J.E. (2009). A task-technology fit view of learning management system impact. Computers \& Education, 52(2), 496-508.

39. Melden, A.I. (1961). Free Action. Routledge and Kegan Paul, London.

40. Mäntymäki, M. and Islam, A.K.M.N. (2014). Social virtual world continuance among teens: Uncovering the moderating role of perceived aggregate network exposure. Behavior \& IT, 33 (5), 536-547.

41. Ogden, J. (2003). Some problems with social cognition models: A pragmatic and conceptual analysis. Health Psychology, 22(4), 424-428.

42. Oliver, R.L. (1980). A cognitive model of the antecedents and consequences of satisfaction decisions. Journal of Marketing Research, 17(11), 460-469. 
43. Popper, K. (1972). Conjectures and refutations: The growth of scientific knowledge. Routledge \& Kegan Paul, London.

44. Rawstorne, P., Jayasuriya, R. and Caputi, P. (2000). Issues in predicting and explaining usage behaviors with the technology acceptance model and the theory of planned behavior: When Usage is Mandatory. In: Proceedings of the 21st International Conference on Information Systems (ICIS 2000), Atlanta, GA, USA.

45. Rodgers, S. and Chen, Q.M. (2002). Post-adoption attitudes to advertising on the internet. Journal of Advertising Research, 42(5), 95-104.

46. Rosenberg, A. (1995). Philosophy of social science. Westview Press, Oxford.

47. Shee, D.Y. and Wang, W.S. (2008). Multi-criteria evaluation of the web-based e-learning system: A methodology based on learner satisfaction and its applications. Computers \& Education, 50(3), 894-905.

48. Silva, L. (2007). Post-positivist review of technology acceptance model. Journal of the Association for Information Systems, 8(4), 255-266.

49. Straub, D., Limayem, M. and Karahanna, E. (1995). Measuring system usage implications for IS theory testing. Management Science, 41(8), 1328-1342.

50. Sumak, B., Hericko, M. and Pusnik, M. (2011). A meta-analysis of e-learning technology acceptance: The role of user types and e-learning technology types. Computers in Human Behavior, 27(6), 2067-2077.

51. Sussman, S.W. and Siegal, W.S. (2003). Information influence in organizations: An integrated approach to knowledge adoption. Information Systems Research, 14(1), 47-65.

52. Szajna, B. (1996). Empirical evaluation of the revised technology acceptance model. Management Science, 42(1), 85-92.

53. Teo, T. and Schaik, P. (2012). Understanding the intention to use technology by preservice teachers: An empirical test of competing theoretical models. International Journal of Human Computer Studies, 28(3), 178-188.

54. Venkatesh, V., Davis, F.D. and Morris, M.G. (2007). Dead or alive? The development, trajectory and future of technology adoption research. Journal of the Association of Information Systems, 8(4), 267-286.

55. Venkatesh, V., Morris, M.G., Davis, G.B. and Davis, F.D. (2003). User acceptance of information technology: toward a unified view. MIS Quarterly, 27(3), 425-478. 